\title{
Effect of spark plasma sintering process on the microstructure and mechanical properties of Nano crystalline hydroxyapatite ceramics prepared by hydrolysis in polyol medium
}

\author{
Abderrahmen Mechay $^{12}$, Hafed El Feki ${ }^{1 *}$, Fréderic Schoenstein ${ }^{2}$, Florent Tétard ${ }^{2}$, Noureddine Jouini ${ }^{2}$ \\ ${ }^{1}$ Laboratoire des Sciences des Matériaux et d'Environnements, Faculté des Sciences de Sfax, 3018 Sfax, Tunisie \\ ${ }^{2}$ Laboratoire des Sciences des Procédés et des Matériaux, CNRS-UPR 9001, Université Paris 13, \\ PRES Sorbonne Paris Cité, 93430 Villetaneuse, France \\ *Corresponding author E-mail: hafed.elfeki@yahoo.fr
}

\begin{abstract}
The aim of the study was to investigate the role of microstructure and porosity on the mechanical behaviour of sintered hydroxyapatite synthesized by polyol process. This process describes a new approach for the synthesis of hydroxyapatite nanoparticles, which involves precipitation and hydrolysis reactions conducted in polyol medium. In the present work a non-conventional technique, spark plasma sintering, was used to consolidate such nanocrystalline apatites at non-conventional, very low temperatures $\left(\mathrm{T}<300^{\circ} \mathrm{C}\right)$ so as to preserve the surface hydrated layer present on the nanocrystals. The hydroxyapatite nanoparticles have been successfully conducted by spark plasma sintering process, resulting in a dense HA compacts. Besides, the sintering behaviour of hydroxyapatite powders at different temperatures ranging was studied. The microstructure, Vickers microhardness, nanoindentation and density are described. Finally, the resulting mechanical properties determined on the microwave sintered samples $\left(\mathrm{E}=136 \pm 4 \mathrm{GPa}, \mathrm{H}_{\mathrm{V}}=8.2 \mathrm{GPa}\right.$, and $\left.\mathrm{K}_{\mathrm{IC}}=1.6 \pm 0.03 \mathrm{MPa} \mathrm{m}^{1 / 2}\right)$ are significantly higher than those usually reported in the literature, whatever the sintering process, and could allow the use of hydroxyapatite for structural applications.
\end{abstract}

Keywords: Hydroxyapatite; Polyol; Spark Plasma Sintering; Mechanical Properties.

\section{Introduction}

There is an increasing demand for synthetic bone and hard tissue replacement materials due to the lack of autograft materials and health risks of allografts. From biological and physiological perspectives, biomaterials for tissue replacement interact with the surrounding in vivo environment chemically, mechanically and morphologically. A successful biomaterial for reconstruction purposes must be similar in the above aspects to the tissue that it is replacing. Chemically, hydroxyapatite (HA) $\left(\mathrm{Ca}_{10}\left(\mathrm{PO}_{4}\right)_{6}(\mathrm{OH})_{2}\right)$ is a synthetic calcium phosphate ceramics that is chemically similar to biological apatite (A. Chaabouni et al. 2014, L. L. Hench 1998, L. L. Hench 2000), It has similar chemical composition and crystal structure to apatite in the human skeletal system and therefore is suitable for bone substitution and reconstruction (E.O. Martz et al. 1997). There are Various synthesis methods of HA, whose degree of success in preparing HA differs significantly from one another, have been reported; including solid-state reaction (R.R. Rao et al. 1997), sol-gel synthesis (A. Deptula et al. 1992, S. Bose et al. 2003), pyrolysis of aerosols (M. Vallet-Regi et al. 1994), hydrothermal reaction (T. Hattori et al 1990), and micro-emulsion (G.K. Lim et al. 1997, K. Sonoda et al. 2002). In the past two decades, several research works have been devoted to the synthesis of inorganic materials (metal, hydroxides and oxides) in polyol medium (D. Jézéquel et al. 1995, L. Poul et al. 2003, L. Poul et al. 2001, S. Lee et al. 2008). The present paper lies within a broader context and has a more general goal which pertains to the production by a bottom-up strategy of nanostructured bioceramics (HA), we have manages to synthesize hydroxoapatite anisotropic nano-particles with very good crystallinity by "chimie douce" methods (A. Mechay et al. 2012) and then the mechanical properties which are bound to the choice of the new approach for the synthesis of hydroxyapatite nanoparticles and their biocompatibility. It involves the compaction of the nanoparticles by spark plasma sintering (SPS) process. The SPS process has attracted considerable attention owing to its high pressure and rapid sintering at a relatively low temperature compared to the conventional sintering process (Y. Sang et al. 1996), besides, the short sintering duration of such process would be advantageous in suppressing exaggerated grain growth (J.R Groza 1994). Spark plasma sintering (SPS) is a relatively new processing technique used for the sintering of various kinds of materials including ceramics, metals, polymers, and composite materials (Rahaman MN 2003). The heating is obtained by the Joule effect caused by a pulsed direct current (DC) passing through a graphite matrix (die) containing the sample. This process enables fast heating and cooling rates, thus limiting uncontrolled crystal growth, and the sintering temperatures under SPS conditions are often lower than those used in conventional methods (Rahaman MN 2003). Therefore, in order to obtain the well sintered specimen with a high level of hardness, we have attempted to sinter ultrafine pure HA with almost full densification using the SPS process, which is expected to have excellent mechanical properties. 


\section{Experimental method}

The nanometric apatitic particles (HA) was synthesized by wet process in polyol medium (ethylene glycol EG). This process consists in pouring a solution ' $\mathrm{B}$ ' containing the cations of $\mathrm{Ca}^{2+}$ (calcium nitrate) drop by drop on a solution ' $\mathrm{A}$ ' containing anions $\mathrm{PO}_{4}{ }^{3-}$ (diammonium phosphate $\left.\left(\mathrm{NH}_{4}\right)_{2} \mathrm{HPO}_{4}\right)$ ) with $\mathrm{Ca} / \mathrm{P}$ ratio 10:6, using a peristaltic pump during $3 \mathrm{~h}$. The $\mathrm{pH}$ of the solution was adjusted to about 10 using an ammonia solution $\left(\mathrm{NH}_{4} \mathrm{OH}\right)$. The precipitates were dried at $100^{\circ} \mathrm{C}$ for $24 \mathrm{~h}$ after aging and washing (A. Mechay et al. 2012). An NMR BRUKER 300MHz (7.1T) spectrometer was used, with cross polarization (CP) and magic-angle spinning (MAS) at $63.633 \mathrm{MHz}$. The MAS rotation rate corresponded to $7 \mathrm{kHz}$. The chemical shift for phosphorus is reported with respect to a $85 \%$ solution of phosphoric acid $\left(\mathrm{H}_{3} \mathrm{PO}_{4}\right)$ as external standard; and tetramethylsilane (TMS) was used as standard for ${ }^{1} \mathrm{H}$ NMR. High-power proton decoupling technique was applied during the recording of ${ }^{31} \mathrm{P}$ NMR spectra. The consolidation process of nanometric HA was realized by a spark plasma sintering (SPS)-515S SYNTEX apparatus. This device consists of a uniaxial press with a maximum force of 200 $\mathrm{kN}$ and a power supply capable of producing a pulsed DC current with a maximum of $8000 \mathrm{~A}$ at $10 \mathrm{~V}$. Apatite powder samples $(1 \mathrm{~g})$ were placed in a $10 \mathrm{~mm}$ graphite die. Thin graphite sheets (Papyex) were used between the powder and the die to facilitate the removal of the consolidated sample. The filled die was then introduced in the treatment chamber under low mechanical pressure in order to ensure electrical contact of the system. The treatment chamber was purged twice under vacuum and then $1 \mathrm{~atm}$ argon pressure was applied during the sintering/consolidation process. The temperature and pressure programmed sequences are described in Fig. 1.

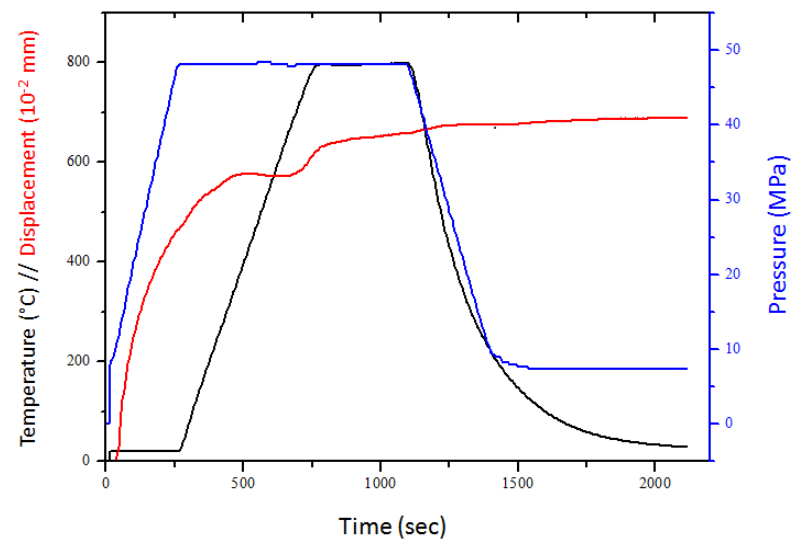

Fig. 1: Schematic Variation of the Temperature, Displacement and the Pressure as Function of Holding Time SPS.

The XRD patterns of the synthesized powders were obtained using a $(\theta-2 \theta)$ Panalytical XPERT PRO MPD diffractometer operating with $\mathrm{Cu} \mathrm{K} \alpha$ radiation. In order to determine the cell parameters, the same XRD patterns were analyzed by the Fullprof program (J. Rodriguez-Carvajal 1993) based on the Rietveld method (H.M. Rietveld 1969). Besides, the density of each sample was measured three times using the Archimedes' principle and the mean value was presented. As for the relative densities, they were calculated by assuming the theoretical density of HA to be $3.156 \mathrm{~g} / \mathrm{cm}^{3}$ (E. Champion et al. 1996). After SPS process, the morphology was studied by scanning electron microscopy using FEI Quanta 200 environmental scanning electron microscope coupled with $(E D A X)$. Micro-hardness measurements were conducted on the perpendicular plane to the pressing direction using a Duramin 40 Vickers device with a test force of $0,490 \mathrm{~N}$ during $7 \mathrm{~s}$. In this study, Vickers micro $(\mu)$-hardness of HA was collected from the literature. The hardness value for each sample was calculated by:

$\mathrm{HV}=0.001854 * \frac{\mathrm{P}}{\mathrm{d}^{2}}$
Where HV, Vickers hardness; P, applied load; d, diagonal indent length.

Fracture toughness $\left(\mathrm{K}_{1 \mathrm{c}}\right)$ of the HA was determined from cracks formed in the Vickers micro $(\mu)$-hardness test. In pure HA, Halfpenny shape crack formation was observed and the Evans and Charles equation was used to determine its fracture toughness (C.B. Ponton et al. 1989):

$\mathrm{K} 1 \mathrm{c}=0.0824 * \frac{\mathrm{P}}{\mathrm{C}^{1.5}}$

The Young's modulus and nano-hardness were obtained by nanoindentation technique using an XP MTS apparatus with a particular Continuous Stiffness Measurement.

\section{Results and discussion}

In order to obtain further information on the bonding of hydroxyapatite, ${ }^{31} \mathrm{P}$ and ${ }^{1} \mathrm{H}$ MAS-NMR measurements were performed. In a first stage, ${ }^{31} \mathrm{P}$ MAS-NMR analyses (on samples dried at $80^{\circ} \mathrm{C}$ ) were carried out (Fig. 2-a). As expected for a hydroxyapatite phase, the ${ }^{31} \mathrm{P}$ NMR signal for pure HA gave rise to a single phosphorus peak around $2.79 \pm 0.1 \mathrm{ppm}$ which is tentatively assigned to the $\mathrm{PO}_{4}{ }^{3-}$ signal and a single carbonate groups $\left(\mathrm{PO}_{4}{ }^{3-}--\mathrm{CO}_{3}{ }^{2-}\right)$ peak of low intensity around $0.97 \mathrm{ppm}$. It may be noted that, in this study, no protonated phosphate (e.g. $\mathrm{HPO}_{4}{ }^{2-}$ ions giving rise to an additional contribution typically around 1.4 (W.P. Rothwell 1980) has been clearly detected in any sample. The NMR peak near -0.18 and $1.05 \mathrm{ppm}$ (fig. 2-b) can be assigned to apatitic $\mathrm{OH}^{-}$ ions from the hydroxyapatite phase (J.P. Yesinowski et al. 1987).

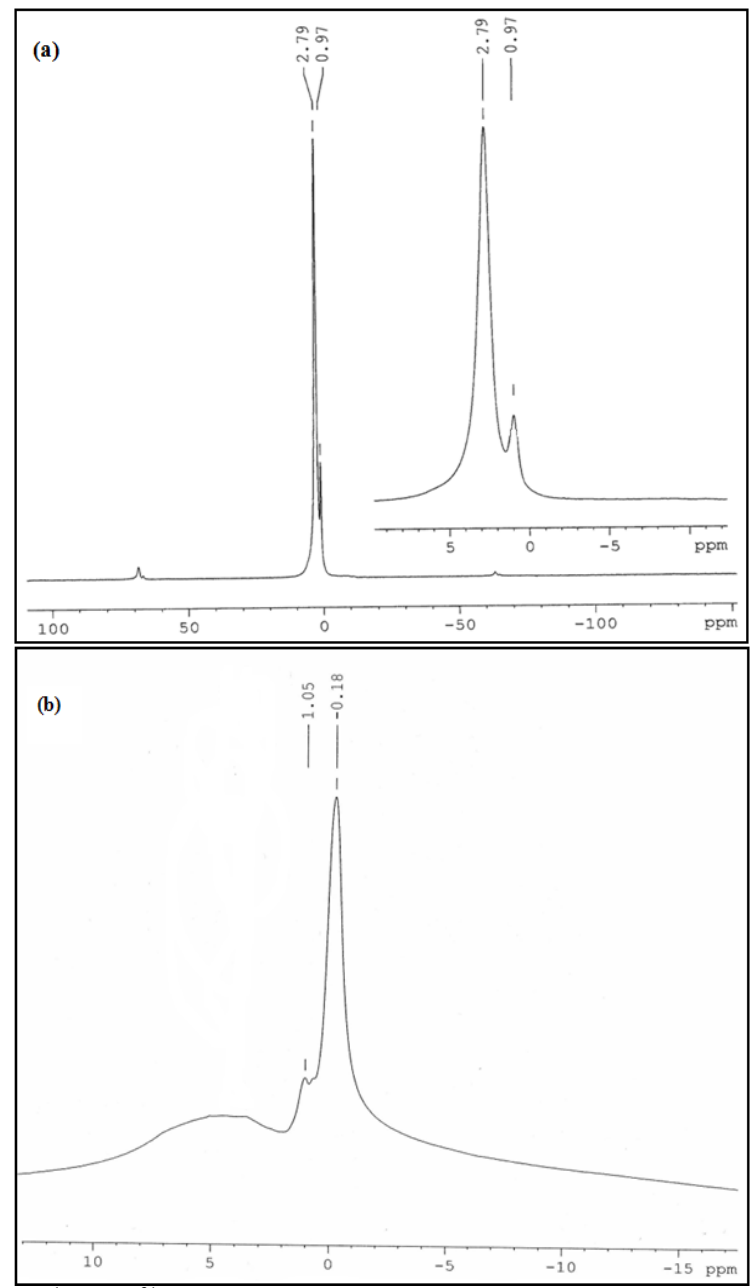

Fig. 2: ${ }^{1} \mathrm{H}$ and ${ }^{31} \mathrm{P}$ MAS NMR Spectra of Hydroxyapatite Powders Dried At $80{ }^{\circ} \mathrm{C}$

Powder X-ray diffraction (XRD) studies were carried out to identify phases and assess the phase-purity and crystallinity of $\mathrm{Ca}, \mathrm{P}$ apatite powders and sintered discs. The purity of the synthesized nanocrystalline apatite of the initial powder was checked by XRD 
(Fig. 3a). The XRD pattern obtained is similar to those obtained in previous works (A. Mechay et al. 2012), and corresponds to a poorly crystallized nanocrystalline apatite, as for bone mineral.

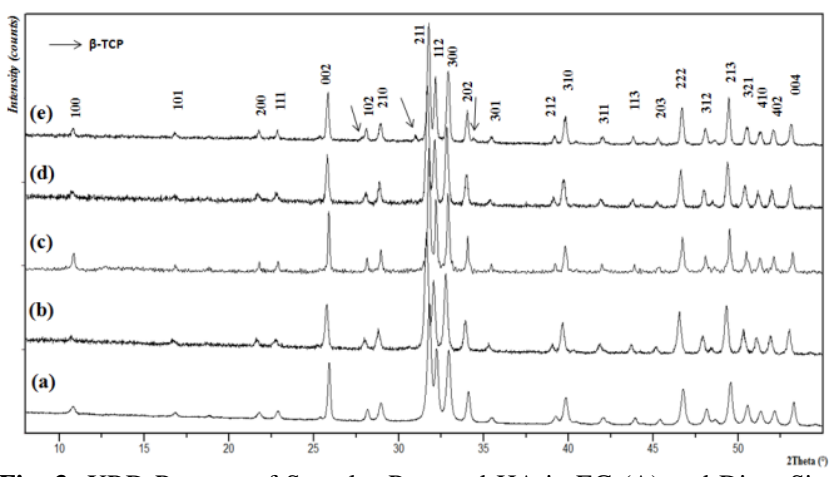

Fig. 3: XRD Patterns of Samples Prepared HA in EG (A) and Discs Sintered at Various Temperatures: (B) $800^{\circ} \mathrm{C}$; (C) $850^{\circ} \mathrm{C}$; (D) $900^{\circ} \mathrm{C}$; (E) $950^{\circ} \mathrm{C}$.

The diffraction peaks were indexed in reference to the hexagonal structure of HA given in the ICDD PDF card 9-432 having lattice parameters $\mathrm{a} \approx \mathrm{b} \approx 9.4249$ (11) $\AA, \quad \mathrm{c} \approx 6.8527$ (9) $\AA$ and space group $\mathrm{P} 63 / \mathrm{m}$. The diffraction diagrams of the X-rays relating to the discs HA fabricated by spark plasma sintering for $5 \mathrm{~min}$ in vacuum at $800^{\circ} \mathrm{C}, 850^{\circ} \mathrm{C}, 900^{\circ} \mathrm{C}$ and $950^{\circ} \mathrm{C}$ is given in Fig.3. The phases were identified by crystallographic software. Although no phase change for the samples sintered at temperatures of $800^{\circ} \mathrm{C}$ to $900^{\circ} \mathrm{C}$, was noted, during the sintering of hydroxyapatite in vacuum at $950^{\circ} \mathrm{C}$, slight decomposition was presented. As indicated by a small peak, the emergence of a very small percentage of the $\beta$-TCP phase can be noticed. The influence of moisture content in atmosphere on the stability of HA at high temperature has been demonstrated by Wang and Chaki (P.E. Wang et al. 1993). The variation of the density of the samples sintered at different temperatures for $5 \mathrm{~min}$ and $50 \mathrm{MPa}$ is shown in table 1 . The measured density increases rapidly with the sintering temperature up to $900^{\circ} \mathrm{C}$. After sintering at $900{ }^{\circ} \mathrm{C}$ for $5 \mathrm{~min}$, the measured density is close to the theoretical value giving a relative density of $99.90 \%$.

Table 1: Summary Table of Density and Fracture Toughness.

\begin{tabular}{|c|c|c|c|}
\hline $\begin{array}{l}\text { Sintered } \\
\text { discs }\end{array}$ & $\begin{array}{l}\text { Density } \\
(\%)\end{array}$ & $\begin{array}{l}\text { Total } \\
\text { Porosity } \\
(\%)\end{array}$ & $\begin{array}{l}\text { Fracture toughness (MPa } \\
\left.\mathrm{m}^{1 / 2}\right)\end{array}$ \\
\hline $800-50-5$ & 85,87 & 14,13 & $0,83 \pm 0,03$ \\
\hline $850-50-5$ & 98,34 & 1,66 & $1,4 \pm 0,02$ \\
\hline $900-50-5$ & 99,8 & 0,2 & $1,6 \pm 0,02$ \\
\hline $950-50-5$ & 99,61 & 0,4 & $0,93 \pm 0,03$ \\
\hline
\end{tabular}

Such a high relative density is reported in literature for HA compacts sintered to $1300^{\circ} \mathrm{C}$ using conventional sintering methods (P.E. Wang et al. 1993). At temperatures above $950^{\circ} \mathrm{C}$, there is a slight decrease in the density due to the decomposition of HA to tricalcium phosphate. As it is well known, $\beta$-TCP has a density of $3.00 \mathrm{~g} / \mathrm{cm}^{3}$ which is lower than that of HA (M.C. Steil et al. 1999) Fig. 4- a, b, c and d show the micrographs of the texture after consolidation of HA SPSed sample for 5 min under $50 \mathrm{MPa}$ pressure at $800^{\circ} \mathrm{C}, 850^{\circ} \mathrm{C}, 900^{\circ} \mathrm{C}$ and $950^{\circ} \mathrm{C}$ respectively and their sizes distributions. Concerning Fig. 4- a and b they show a very small amount of rounded inter-granular porosity $(<70-100 \mathrm{~nm})$, suggesting a high sintered density. The average grain size was determined to be $130 \mathrm{~nm}\left( \pm 19 \mathrm{~nm} ; 200\right.$ grains sampled) at $800^{\circ} \mathrm{C}$ and $150 \mathrm{~nm}\left( \pm 23 \mathrm{~nm} ; 200\right.$ grains samples) at $850^{\circ} \mathrm{C}$. As for Fig. 4- c and $d$ show a fractured surface of HA sample revealing no obvious porosity, consistent with $100 \%$ theoretical density using Archimedes' method. The average grain size was measured to be 160 $\mathrm{nm}$ and $170 \mathrm{~nm}( \pm 26 \mathrm{~nm} ; 200$ grains sampled) respectively. This suggests that the $50^{\circ} \mathrm{C}$ increase in sintering temperature (from $850^{\circ} \mathrm{C}$ to $900^{\circ} \mathrm{C}$ ) caused no significant change in the average grain size; however, it was required to completely eliminate porosity.
Archimedes's method suggested that both these samples were $100 \%$ dense.
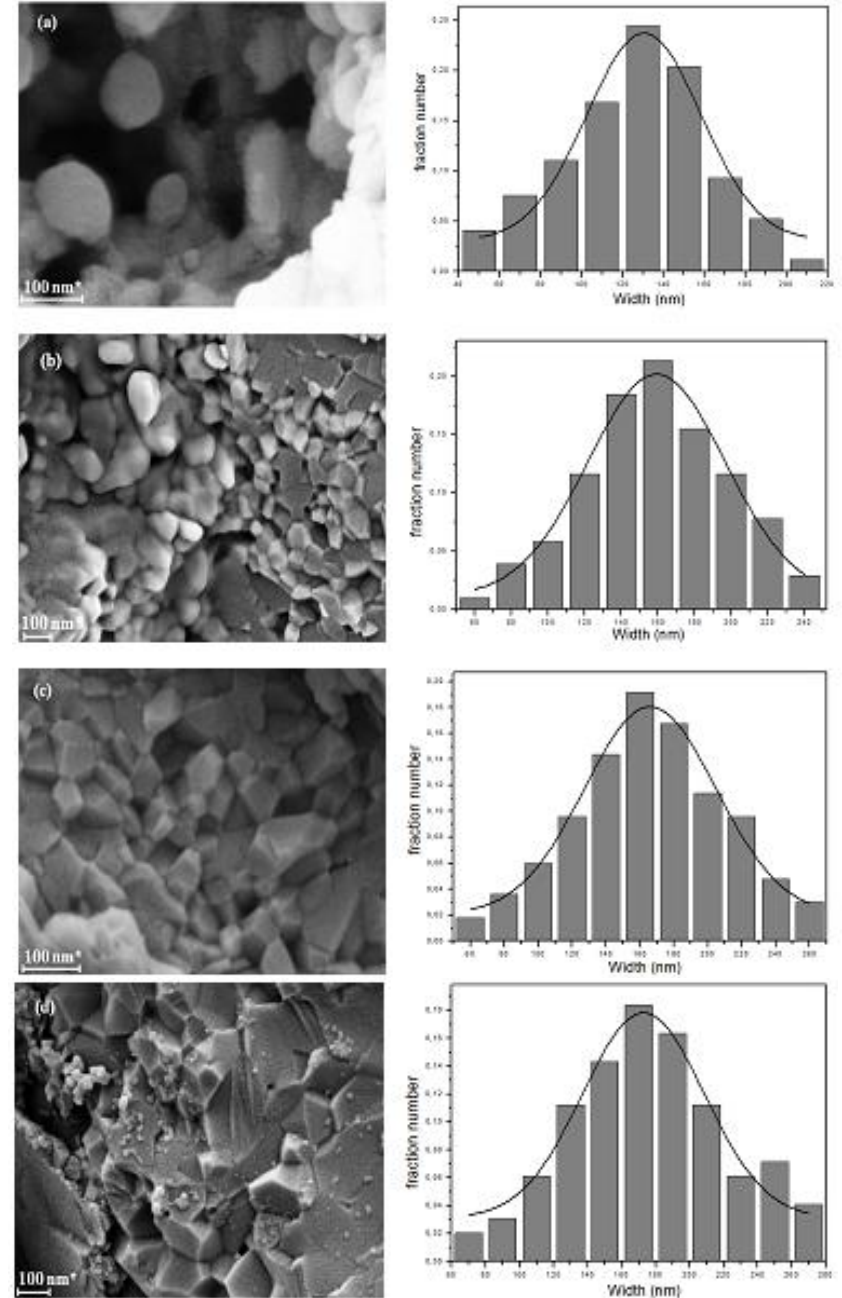

Fig. 4: SEM Images of Sample HA Spsed for 5 Min under $50 \mathrm{Mpa}$ and their Sizes Distributions: (A) $800^{\circ} \mathrm{C}$; (B) $850^{\circ} \mathrm{C}$; ( C) $900^{\circ} \mathrm{C}$; (D) $950^{\circ} \mathrm{C}$, the Fit of the Distribution by A Lorentzian Is Also Reported (Black Line).

Fig.5 shows the variation of micro-hardness according to sintering temperature. It is worthwhile to note that the hardness increased rapidly when the compound was heated from $800^{\circ} \mathrm{C}$ to $850^{\circ} \mathrm{C}$, whereas it slightly increased between $850^{\circ} \mathrm{C}$ and $900^{\circ} \mathrm{C}$ and then stabilizes until $950^{\circ} \mathrm{C}$. The hardness could be affected by both relative density and grain size. Pores in ceramics have no resistance to applied stress, so materials of higher porosity have lower apparent hardness than dense materials. In addition to the effects of porosity, the grain size also influences hardness. Actually, smaller grain size increases the frequency with which dislocations encounter grain boundaries, thus requiring larger stresses for deformation to occur (T. Li et al. 2007).

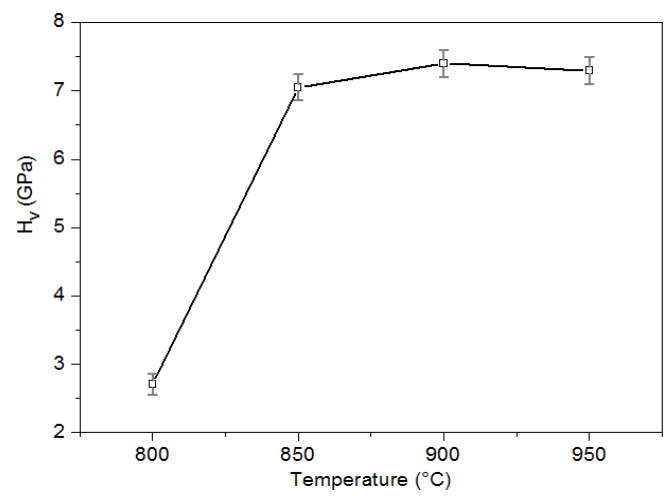

Fig. 5: The Vickers Hardness of Various Sintered Samples vs. Sintering Temperature. 
These results are in good agreement with those obtained previously, which showed that the density increases rapidly between the temperatures $800^{\circ} \mathrm{C}$ and $900^{\circ} \mathrm{C}$. Indeed, previous studies (Y.W. GU Et Al 2002) have clearly confirmed these statements and shown that hardness is an increasing function of the material density.

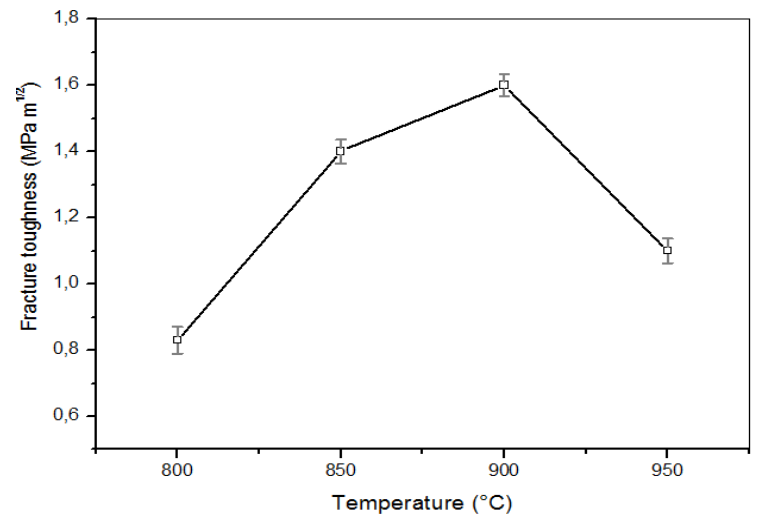

Fig. 6: Effect of Sintering Temperature on the Fracture Toughness of HA Sintered By SPS

Fig. 6 shows the effect of sintering temperature on the fracture toughness for various compacts. There is no significant change in the fracture toughness under different temperatures. Slight increase in fracture toughness in the temperature range of $800^{\circ} \mathrm{C}$ $900^{\circ} \mathrm{C}$ and slight decrease in the temperature range of $950^{\circ} \mathrm{C}$ can be observed. The variation of fracture toughness as a function of the sintering temperature is due to the combined influence of density and grain size. Therefore, the increase in the fracture toughness appears fairly limited. It has also been reported that the fracture toughness of sintered materials decreases only slightly with increasing porosity (L. Coronel et al. 1990). There is slightly decreased in the fracture toughness in the temperature range from $900^{\circ} \mathrm{C}$ to $950^{\circ} \mathrm{C}$. This is due to the fact that the density decreases slightly and the average grain size grows from 130 to $160 \mathrm{~nm}$. A decrease of fracture toughness with increasing grain size is usually observed in compacts when the mechanism is transgranular because the major contribution to cracking resistance is related to the crossing of the grain boundaries (S.W. Freiman 1988). This indicates that fast sintering at high temperatures is beneficial for the improvement of the fracture toughness. The nano-hardness $\left(\mathrm{H}_{\mathrm{B}}\right)$ and Young modulus (E) of HA sintered at different temperatures is shown in fig.7. It can be noted that the hardness which remained almost constant over the displacement has shown that the interfacial bonding strength is high and the microcracks are not introduced into composite materials. In general, Young's modulus decreases when the interfacial bonding strength is weak or when microcracks are introduced in the composites. Young's modulus values were reported in the literature by Y. W. Gu and al (Y.W. $\mathrm{Gu}$ et al 2002), who provided Young's modulus values comparable or smaller compared to those obtained in this research work.

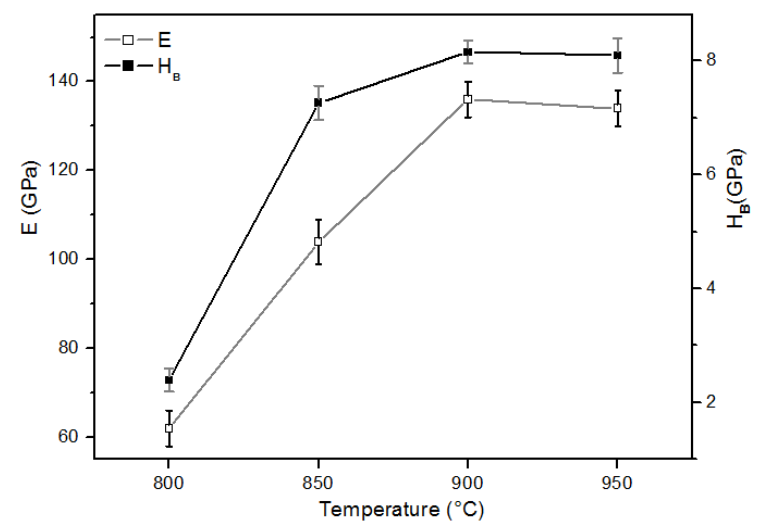

Fig. 7: Young's Modulus (E) And Berkovich Hardness (HB) Measured as A Function of the Sintering Temperature.

\section{Conclusions}

Nanocrystalline apatite can successfully be consolidated by spark plasma sintering. This physico-chemical study sheds more light on the possibility of consolidating hydroxyapatite powders by SPS at different temperatures while retaining the initial advantageous characteristics of the powder. By means of the SPS process, HA powders were sintered and the microstructure and mechanical properties of the sintered compacts were investigated. HA powders were sintered to near theoretical density (99.8\%) and the hardness measurements revealed that a high hardness of more than $9 \mathrm{GPa}$ was achievable after spark plasma sintering technique.

\section{References}

[1] Chaabouni, C. Chtara, A. Nzihou, H. El Feki, Study the effects of calcinations and evolution of crystallographic parameters of two Tunisian natural phosphates, International Journal of Advanced Chemistry, 2 (1) (2014) 24-26.

[2] Deptula, W. Oada, T. Olczak, A. Borello, C. Alvani, A. Bartolomeo, Preparation of spherical powders of hydroxyapatite by sol-gel process, J Non-Cryst Sol 147-148 (1992) 537.

[3] Mechay, H. Elfeki, F. Schoenstein, N. Jouini, Nanocrystalline hydroxyapatite ceramics prepared by hydrolysis in polyol medium, Chemi Phys Lett 541 (2012) 75.

[4] C.B. Ponton, R.D. Rawlings, Vickers indentation fracture toughness test Part I. Review of literature and formulation of standardized indentation toughness equation, Mater. Sci. Technol. 5 (1989) 865-872.

[5] D. Jézéquel, J. Guenot, N. Jouini, F. Fiévet, Submicrometer zinc oxide particles: Elaboration in polyol medium and morphological characteristics, J Mater Resea 10 (1995) 77-83.

[6] E. Champion, S. Gautier, D. Bernache-Assollant, Characterization of hot pressed $\mathrm{Al}_{2} \mathrm{O}_{3}$-platelet reinforced hydroxyapatite composites, J Mater Sci: Mater in Medic 7 (1996) 125-130.

[7] E.O. Martz, V.K. Goel, M.H. Pope, J.B. Park, Materials and design of spinal implants, J. of Biomed. Mater. Resea. 38 (1997) 267.

[8] G.K. Lim, J. Wang, S.C. Ng, C.H. Chew, L.M. Gan, Processing of hydroxyapatite via microemulsion and emulsion route, Biomat 18 (1997) 1433.

[9] H.M. Rietveld, A profile refinement method for nuclear and magnetic structures, J Applied Crystallography 2 (1969) 65-71.

[10]J.P. Yesinowski., H. Eckert, High-Resolution Structural Insights into Bone: A Solid-State NMR Relaxation Study Utilizing Paramagnetic Doping .J. Am. Chem. Soc. 109 (1987) 6274.

[11]J. Rodriguez-Carvajal, Recent advances in magnetic structure determination by neutron powder diffraction, Physica B: Condensed Matter 192 (1993) 55.

[12]J.R Groza, Consolidation of atomized NiAl powders by plasma activated sintering process, Scripta. Metallurgica et Materialia 30 (1994) 47.

[13]K. Sonoda, T. Furuzono, D. Walsh, K. Sato, J. Tanaka, Influence of emulsion on crystal growth of hydroxyapatite, Sol Sta Ioni 151 (2002) 321.

[14]L. Coronel, J.P. Jernot, F. Osterstock, Microstructure and mechanical properties of sintered glass. J. Mater. Sci. 25 (1990) 4866-72.

[15]L. L. Hench, Biomaterials: a forecast for the future, Biomaterials 19 (1998) 1419

[16]L. L. Hench, The challenge of orthopaedic materials, Current Orthopaedics, 14 (2000) 7.

[17]L. Poul, S. Ammar, N. Jouini, F. Fievet, F. Villain, Synthesis of inorganic compounds (metal, oxide and hydroxide) in polyol medium : A versatile route related to the sol-gel process, J Sol-Gel Sci Tech 26 (2003) 261

[18]L. Poul, S. Ammar, N. Jouini, F. Fievet, F. Villain, Metastable solid solutions in the system $\mathrm{ZnO}-\mathrm{CoO}$ : synthesis by hydrolysis in polyol medium and study of the morphological characteristics, Sol Sta Sci 3 (2001) 31 .

[19]M.C. Steil, J. Fouletier, M. Kleitz, P. Labrune, BICOVOX: Sintering and grain size dependence of the electrical properties, J Europ Ceram Soc 19 (1999) 815

[20]M. Vallet-Regi, M.T. Gutiérrez-Rios, M.P. Alonso, M.I. Frutos, S. Nicolopoulos, Hydroxyapatite particles synthesized by pyrolysis of an aerosol, J Sol Stat Chemis 112 (1994) 58.

[21]P.E. Wang, T.K. Chaki, Sintering behaviour and mechanical properties of hydroxyapatite and dicalcium phosphate, J Mater Sc: Mater in Medic 4 (1993) 150-58. 
[22] Rahaman MN. Ceramic processing and sintering. 2nd ed. Boca Raton, FL: CRC Press (2003).

[23]R.R. Rao, H.N. Roopa, T.S. Kannan, Solid state synthesis and thermal stability of HAP and HAP- $\beta$-TCP composite ceramic powders, Mater in Medici 8 (1997) 511

[24]S. Bose, S.K. Saha, Synthesis of hydroxyapatite nanopowders via sucrose template sol-gel method, J Amer Ceram Soc 86 (2003) 1055.

[25] S. Lee, S. Jeong, D. Kim, S. Hwang, M. Jeon, J. Moon, ZnO nanoparticles with controlled shapes and sizes prepared using a simple polyol synthesis, Superlattices and Microstructures 43 (2008) 330.

[26]S.W. Freiman, Brittle fracture behavior of ceramics, J. Am. Ceram. Soc. Bull. 67 (1988) 392-402.

[27]T. Hattori, Y. Lwadate, Hydrothermal preparation of calcium hydroxyapatite powders, J Amer Ceram Soc 73 (1990) 1803.

[28]T. Li, Q. Li, J.Y.H. Fuh, P.C. Yu, L. Lu, C.C. Wu, Effects of AGG on fracture toughness of tungsten carbide, Mater Sci and Eng A 445-446 (2007) 587.

[29]W.P. Rothwell., J.S. Waugh., J.P. Yesinowski, High-resolution variable- temperature ${ }^{31} \mathrm{P}$ NMR of solid calcium phosphate. J. Am. Chem. Soc. 102 (1980) 2637.

[30]Y. Sang, J.R. Groza, T.S. Sudarshan, K. Yamazaki, Diffusion donding of boron nitride on metal substrates by plasma activated sintering (PAS) process, Scripta Materialia 34 (1996) 1383-86.

[31]Y.W. Gu, N.H. Loha, K.A. Khora, S.B. Tora, P. Cheangb, Spark plasma sintering of hydroxyapatite powders, Biomaterials 23 (2002) 37. 